\title{
A METODOLOGIA DE LUIGI FERRAJOLI PARA A PRODUÇÃO DE PRONUNCIAMENTOS JUDICIAIS PENAIS.
}

\begin{abstract}
Ana Carolina Santana ${ }^{1}$
Resumo: Este trabalho objetiva analisar o pensamento de Luigi Ferrajoli acerca da necessidade de delimitação de regras a serem seguidas pelo julgador na produção do pronunciamento judicial. As citadas regras possuem a função de caracterizar as decisões judiciais como produto da ciência, para isso é necessária a observância de um método que possua cientificidade. No âmbito penal, esse método baseia-se no sistema garantista, desenvolvido por Luigi Ferrajoli, que procura distanciar as ideologias e preconceitos do juiz, além de objetivar a análise probatória.
\end{abstract}

Palavras-chave: sistema garantista; regras; metodologia; pronunciamento judicial; cientificidade

\section{THE METHODOLOGY OF LUIGI FERRAJOLI FOR THE PRODUCTION OF PUNISHED JUDICIAL PRONOUNCEMENTS.}

\begin{abstract}
This paper aims to analyze the thinking of Luigi Ferrajoli about the need for delimitation of rules to be followed by the judge in the production of the judicial pronouncement. The aforementioned rules have the function of characterizing judicial decisions as the product of science, for this it is necessary to observe a method that possesses scientific scope. In the criminal sphere, this method is based on the guarantor system, developed by Luigi Ferrajoli, who tries to distance the ideologies and prejudices of the judge, besides objectifying the probative analysis.
\end{abstract}

Keywords: guarantor system; rules; methodology; judicial pronouncement; scientific.

\section{INTRODUÇÃO}

"Assim como o xadrez pode ser definido em função de regras que lhe são próprias, a Ciência pode ser definida por meio de regras metodológicas" (POPPER, 2008, p. 56).

Este trabalho parte do pressuposto do Direito enquanto ciência, ainda que este não seja um entendimento unânime. Em razão disso, o produto da aplicação da

\footnotetext{
${ }^{1}$ Graduada em Direito pela Universidade Federal de Sergipe; Mestranda em Direito pela Universidade Federal de Sergipe; Juíza de Direito do Tribunal de Justiça do Estado de Pernambuco; Professora convidada da Especialização em Ciências Criminais da Faculdade de Integração do Sertão em Pernambuco.
} 
ciência jurídica deve guardar relação com a cientificidade, ou seja, com o método científico.

Bem verdade que a produção de pronunciamentos judiciais exige um esforço interpretativo que, teoricamente, fugiria à objetividade buscada pelo método científico. Entretanto, Luigi Ferrajoli desenvolve, através do sistema garantista, regras metodológicas com o objetivo de identificar, na medida máxima, a decisão judicial enquanto produto da ciência.

Este trabalho tem por objetivo analisar a construção, empreendida por Ferrajoli, da metodologia necessária para a superação da predominância política nas decisões judiciais e a aproximação do caráter científico.

Inicialmente analisaremos a epistemologia garantista, desenvolvida pelo citado autor, compreendendo seus elementos e suas dimensões, verificando que a construção das regras metodológicas para o reconhecimento da decisão judicial enquanto produto da ciência remonta à produção legislativa. O legislador é responsável pelo início do processo metodológico, devendo fazer uso de termos que sejam capazes de conferir objetividade à futura análise judicial.

Após, continuando a análise da teoria garantista, mais especificamente das regras por ela desenvolvidas para orientar pronunciamentos judiciais, analisaremos em que medida a separação dos poderes judiciais auxilia na compreensão das esferas de discricionariedade do julgador. Observaremos que Luigi Ferrajoli separa esses poderes em quatro e que, três deles possuem caráter predominantemente objetivo.

Nesse sentido, visualizaremos a possibilidade de aplicação de métodos científicos no exercício dos três primeiros poderes utilizados pelo juiz para construir o pronunciamento judicial, restando ao último a esfera ético política que, por sua vez, não deve ser vista como um empecilho ao reconhecimento da cientificidade das decisões judiciais, quando respeitados os limites do sistema garantista.

Por fim, concluiremos que a ciência jurídica exige a aplicação do método científico, no que for cabível, tendo em vista as peculiaridades da referida ciência, na produção dos pronunciamentos judiciais. Não será defendida a posição do juiz enquanto uma máquina, isento de preconceitos e ideologias, mas será demonstrado que o afastamento desses valores é medida imprescindível à imparcialidade. 
Por sua vez, o referido afastamento somente é possível se existirem regras previamente delimitadas acerca dos poderes do juiz e, consequentemente, observadas e respeitadas por ele.

\section{NOTAS INTRODUTÓRIAS ACERCA DA EPISTEMOLOGIA GARANTISTA}

O modelo de direito penal atualmente concebido é produto do iluminismo e do liberalismo. Após os horrores vividos na segunda guerra mundial com o nazismo e o facismo, além de outros modelos autoritários que se instalaram em diversos países, restou demonstrado que o positivismo jurídico, ainda que fundamente o princípio da estrita legalidade, possibilita o desenvolvimento de modelos penais absolutos, ausentes de limites quanto ao poder normativo do soberano.

O ordenamento jurídico como sistema foi defendido por Norberto Bobbio, que enunciou a existência da norma fundamental como pressuposto para a unidade desse sistema. A referida norma teria a possibilidade de relacionar-se, direta ou indiretamente, com todas as normas do ordenamento jurídico (BOBBIO, 1995).

No âmbito penal, a unidade do citado sistema depende da configuração dos princípios garantistas como esquema epistemológico de identificação do desvio penal. Ele assegura a racionalidade e confiabilidade do juízo em seu grau máximo, em detrimento de modelos penais absolutos que já foram consensualmente aceitos e aplicados (FERRAJOLI, 2002). Desta feita, o que se busca é a limitação do poder punitivo estatal e a tutela do cidadão contra toda e qualquer arbitrariedade.

A Constituição Federal Brasileira, promulgada em 1988, após a experiência de supressão e aniquilação de direitos, ocorrida na ditadura militar, adota o posicionamento garantista principalmente quando eleva a princípio fundamental da nossa República federativa a dignidade da pessoa humana.

O ser humano é posicionado no centro do ordenamento jurídico, isso significa que toda interpretação do sistema deve ser pautada no respeito à condição do cidadão brasileiro como sujeito de direitos e garantias.

Segundo Luigi Ferrajoli, os elementos constitutivos da epistemologia garantista estão ligados à definição legislativa e à comprovação, em juízo, do desvio punível. De forma que, quanto ao primeiro elemento há a correspondência ao conjunto 
de garantias penais e, quanto ao segundo elemento, essa correspondência se dá ao conjunto de garantias processuais (FERRAJOLI, 2002).

Ao conjunto de garantias penais é dado o nome de convencionalismo penal e este relaciona-se com o princípio da legalidade estrita na esfera legislativa, ou seja, no âmbito de determinação abstrata das condutas que merecem ser punidas.

$\mathrm{Na}$ epistemologia garantista, o princípio da legalidade estrita exige duas condições, quais sejam, o caráter procedimental, previsto em lei, para a definição da conduta punível e o caráter empírico, referente às situações dos fatos, ou seja, às situações nas quais essas condutas são legalmente definidas (FERRAJOLI, 2002).

Nesse sentido, “o princípio da legalidade é enunciado por meio da expressão latina "nullum crimen, nulla poena sine lege"” (TOLEDO, 1994, p. 21). Percebemos que essa expressão possui relação direta com o caráter procedimental da função legislativa, aquela primeira condição do princípio em análise.

Por outro lado, há também o desdobramento que enuncia outra expressão latina "nulla poena sine crimine et sine culpa", e quanto a esta é possível observar que sua relação se dá com as figuras objetivas de comportamento, as figuras empíricas, e não diz respeito às figuras subjetivas, sejam elas de status ou de autor (FERRAJOLI, 2002). Trata-se, nesse último caso, da segunda condição do princípio da legalidade, a que se refere aos fatos propriamente ditos.

Em matéria penal, essa primeira condição referente ao caráter procedimental do princípio da legalidade é denominada de princípio da reserva legal (FERRAJOLI, 2002). Esse princípio limita-se a prescrever a submissão do juiz à lei, de modo que este afaste qualquer julgamento moral, devendo se restringir à aplicação da lei.

Por sua vez, a segunda condição, referente ao caráter empírico, além de abranger o princípio da reserva legal enuncia que a submissão do juiz é somente à lei. Desse modo, Ferrajoli faz a distinção entre o princípio da mera legalidade, que equivale à reserva legal e é um mandamento dirigido principalmente aos juízes, que possuem a função de aplicar a lei e, do outro lado, o princípio da estrita legalidade, que designa a reserva absoluta da lei, ou seja, uma norma dirigida ao legislador a quem compete confeccionar as formulações legais de forma taxativa e com precisão empírica (FERRAJOLI, 2002). 


\section{A METODOLOGIA DE LUIGI FERRAJOLI PARA A PRODUÇÃO DE PRONUNCIAMENTOS JUDICIAIS PENAIS}

Conforme já explanado, o princípio da legalidade que se desdobra em princípio da estrita legalidade e é dirigido principalmente ao legislador restringe a atividade legislativa, isso porque a formulação legal deve ser dirigida a condutas e não a pessoas. O sistema penal não mais admite a formulação de normas constitutivas que exponham pessoas, a normatização deve ser regulamentar, fundamentada em figuras empíricas, em condutas indesejáveis para a sociedade.

De igual forma, o princípio da mera legalidade também detém um caráter restritivo, nesse caso quanto à atividade jurisdicional. $\mathrm{O}$ juiz deve ser submisso somente à lei, isso significa que nenhum julgamento passará pelo viés moralista ou contra legem. Ainda que a atividade interpretativa tenha como característica imanente a criatividade, isso não autoriza a confusão lógica que atualmente tem sido empreendida nos tribunais pátrios quanto aos enunciados jurídicos e enunciados morais.

"O que confere relevância penal a um fenômeno não é a verdade, a justiça, a moral, nem a natureza, mas somente o que, com autoridade, diz a lei" (FERRAJOLI, 2002, p. 31). Verificamos assim que o conjunto de garantias penais, também chamado de convencionalismo penal, e aqui analisado como o primeiro elemento da epistemologia garantista, exclui a caracterização extralegal ou ontológica das condutas indicadas na lei. E esta última deve fazer essa indicação de forma taxativa, através de condutas determinadas, também conhecida como tipos penais fechados.

As consequências imediatas advindas desse convencionalismo penal são a garantia para o cidadão quanto à intangibilidade de sua liberdade e a igualdade jurídica. Desse modo, apenas é punível o que está proibido em lei prévia, orientando assim o cidadão em sua conduta, não podendo este ser cerceado em sua liberdade por ação não prevista em lei. Por sua vez, a igualdade jurídica de todos os cidadãos perante a lei enuncia que a normatização recai sobre condutas determinadas, não sobre pessoas determinadas.

O segundo elemento constitutivo da epistemologia garantista diz respeito ao conjunto de garantias processuais que estão ligadas à comprovação jurisdicional do desvio punível. A esse conjunto de garantias Ferrajoli (2002) denomina de cognitivismo processual e o associa ao primeiro elemento, ao da definição legislativa, como sendo sua condição de efetividade. 
Observamos que não poderia ser diferente. O sistema mantém sua unidade quando esses dois elementos são efetivados. É necessária a definição precisa de tipos penais fechados que proíbam determinados comportamentos, independentemente das pessoas que os pratiquem, bem como a correta aplicação da lei, por meio de decisões sem justificativas morais ou ideológicas, mas sim amparadas nas regras metodológicas garantistas.

Nesse sentido, o cognitivismo processual afeta as decisões judiciais no âmbito da sua motivação, ou seja, quanto aos motivos de fato ou de direito que foram justificantes para a decisão proferida. Também denominado de princípio de estrita jurisdicionariedade, exige duas condições: "a verificabilidade ou refutabilidade das hipóteses acusatórias, em virtude de seu caráter assertivo, e sua comprovação empírica em virtude de procedimentos que permitem tanto a verificação como a refutação" (FERRAJOLI, 2002, p. 32).

Assim, não basta que apenas o legislador sofra restrição quanto à elaboração de leis que sejam regulamentares em detrimento das leis puramente constitutivas, é fundamental que os julgadores também apliquem a lei de forma objetiva, não priorizando a verificação das pessoas e seus respectivos status, mas sim dos fatos cometidos.

O princípio da estrita legalidade, no seu duplo aspecto formal e empírico, somente será satisfeito se o juízo penal, assim como o legislador, dispense o caráter constitutivo e tenha caráter recognitivo das normas e cognitivo dos fatos por elas regulados (FERRAJOLI, 2002).

Quanto aos requisitos da verificabilidade e refutabilidade das hipóteses acusatórias que deverão ser analisados no momento da decisão judicial, Karl Popper já fazia referência a eles como elementos da ciência. Ainda que Popper se utilizasse do critério de demarcação inerente à lógica indutiva como o da falseabilidade e não a verificabilidade (POPPER, 2008), a refutabilidade é requisito contido em todo método, uma vez que as hipóteses são colocadas a prova através das refutações. "O trabalho do cientista consiste em elaborar teorias e pô-las à prova" (POPPER, 2002, p. 31).

A verificabilidade e refutabilidade empregadas no processo penal caracterizam o modelo normativo que eleva aquele a processo de cognição ou de comprovação, no qual a decisão acerca da conduta prevista na lei penal tem caráter de 


\section{A METODOLOGIA DE LUIGI FERRAJOLI PARA A PRODUÇÃO DE PRONUNCIAMENTOS JUDICIAIS PENAIS}

procedimento probatório de tipo indutivo, excluindo as valorações e tendo como base as afirmações ou negações, sejam de fato ou de direito, que possam ensejar em verdade ou falsidade processual. (FERRAJOLI, 2002). Nesse ponto, podemos afirmar que a elaboração de pronunciamento judicial muito se assemelha à elaboração de teorias científicas.

Observamos, assim, que Ferrajoli, ao desenvolver a epistemologia garantista, concebe a jurisdição como atividade cognitiva que complementa as atividades convencionalista e empírica da legislação. Essa concepção, segundo o autor, possui dois resultados caracterizados como ético-políticos da cultura penal desenvolvida a partir do iluminismo, o primeiro deles é o valor da certeza na caracterização, no caso concreto, da conduta delitiva; o segundo é a separação entre direito e moral (FERRAJOLI, 2002).

A epistemologia garantista é um sistema ideal, representando um limite de aplicação do sistema penal. Não significa a possibilidade de realização na sua inteireza, mas serve de norte à aplicação do direito, ao julgador. Este último não é uma máquina, ou seja, não se encontra isento de sentimentos e ideologias, além da moralidade que atualmente tem contaminado sobremaneira o espaço jurídico.

Desse modo, considerando que não é possível exigir do julgador a total abstração de suas ideologias e sentimentos para proceder à atividade jurisdicional, resta verificado que o silogismo judicial perfeito não existe, tratando-se de uma ilusão metafísica (FERRAJOLI, 2002). E é por este fato que se torna imprescindível, principalmente na seara penal, a fixação de limites ao poder interpretativo dos julgadores, tal como propõe a epistemologia garantista.

Popper defende a tese de que uma experiência subjetiva ou até mesmo um sentimento de convicção jamais seriam capazes de justificar um enunciado científico e de que, no âmbito da ciência, a experiência subjetiva não desempenha nenhum papel a não ser o de objeto de uma investigação empírica (POPPER, 2008). Desta feita, um enunciado jamais poderia ser justificado por um sentimento de convicção, ainda que este fosse intenso.

A exigência da objetividade dos enunciados científicos afasta a redução da verdade a uma mera análise amparada em experiências pessoais. 
Entretanto, Karl Popper, assim como Luigi Ferrajoli, percebem que a objetividade em sua plenitude não passa de um conceito metafísico. A partir do momento que a ciência, bem como a decisão judicial, é proveniente da aplicação de um método por alguém que já possui convicções pessoais, ou seja, hipóteses psicológicas, é necessário desenvolver um método que afaste na medida máxima essas convicções da confecção do produto final.

Uma das razões que levaram Popper a propor o método como característica das ciências empíricas foi justamente a maneira como manipulamos os sistemas científicos (POPPER, 2008).

Por sua vez, a epistemologia garantista não defende o mecanicismo na aplicação da lei, pois essa hipótese além de impossível não se coaduna com a atividade interpretativa jurisdicional. Compreendemos que o que se propõe é a utilização da atividade valorativa em favor do acusado, como limite ao poder punitivo estatal, ou seja, ainda que se configure uma valoração, ela está devidamente normatizada. Essa é a possibilidade. Entretanto, o método empregado em algumas decisões judiciais é absolutamente contrário ao acusado e com uma valoração moral, longe da objetividade defendida por Popper como configuradora da cientificidade.

Analisaremos no próximo tópico a aplicação das regras delimitadas pelo sistema garantista, através do exercício do poder judicial, que Ferrajoli didaticamente o distingue em quatro.

\section{MÉTODO GARANTISTA DE CONSTRUÇÃO DOS PRONUNCIAMENTOS JUDICIAIS PENAIS}

Para Ferrajoli, existem quatro aspectos do poder do juiz, quais sejam: o poder de denotação ao qual corresponde a verificação jurídica, o poder de comprovação das provas ao qual corresponde a verificação fática, o poder de conotação no qual se insere o discernimento equitativo e o poder de disposição também podendo ser denominado de poder de valoração ético-política (FERRAJOLI, 2002)

Verificamos que a distinção feita pelo citado autor para analisar a metodologia aplicada aos pronunciamentos judiciais na seara penal é bastante didática. Esclarece, na verdade, quatro fases distintas do método aplicado à elaboração das 


\section{A METODOLOGIA DE LUIGI FERRAJOLI PARA A PRODUÇÃO DE PRONUNCIAMENTOS JUDICIAIS PENAIS}

decisões judiciais e sua medida de aproximação ou distanciamento dos métodos científicos.

Os dois primeiros poderes atribuídos ao juiz, ou seja, o poder de denotação e o poder de comprovação probatória estão vinculados às decisões acerca da verdade processual. Nesse ponto, verificamos que as decisões possuem interferência nos processos que compõem a motivação judicial, são estes o processo de inferência indutiva ou prova, que diz respeito à verdade fática, e o processo de inferência dedutiva ou subsunção, que faz referência à verdade jurídica das premissas (FERRAJOLI, 2002).

Antes de adentrarmos na análise de cada um dos citados poderes, é imperioso que se faça uma breve explanação acerca da linguagem penal. Isso porque tanto as condições de verificabilidade quanto às de falseabilidade dependem da semântica da linguagem (FERRAJOLI, 2002). Nesse sentido, o uso dos termos "verdadeiro" e "falso", a respeito de qualquer afirmação, devem ser vistos com cautela, dentro do contexto da linguagem aplicada na referida afirmação.

Percebemos que a utilização de termos indeterminados na lei penal abre margem significativa para aplicação da discricionariedade pelo juiz. Dessa forma, a linguagem, quanto mais indeterminada é menos apropriada ao processo de refutação, uma vez que possui motivação amparada em valores, juízos de valor, e não em argumentos verificáveis objetivamente.

Concluímos assim, que o melhor emprego da linguagem no âmbito penal é no sentido da exatidão dos termos, para que o processo de subsunção se torne mais seguro e confiável. São os conhecidos tipos penais fechados que consolidam a ideia de uma codificação penal coerente com a perspectiva garantista.

Analisaremos a seguir cada um dos poderes elencados por Ferrajoli no desenvolvimento de sua metodologia de produção das decisões judiciais.

\subsection{Poder de denotação}

Pois bem, voltando à análise dos poderes atribuídos ao juiz, enumerados por Ferrajoli em quatro, sendo o primeiro o poder de denotação, observamos que este primeiro poder diz respeito à verificabilidade jurídica. A verificação, além de jurídica, pode ser fática, esta última possui como pressuposto a linguagem comum, que também 
é utilizada nos pronunciamentos judiciais, por sua vez, a verificação jurídica relacionase com a linguagem técnica, prevista nas codificações, em especial no código penal.

Conforme o princípio da legalidade estrita, já visto anteriormente como integrante da epistemologia garantista de Ferrajoli, a verificabilidade e a falseabilidade jurídica dependem diretamente das definições legais que prescrevem os tipos penais abstratamente considerados, ou seja, os conceitos devem ser suficientemente precisos para fins de denotação jurídica, ou subsunção jurídica, das condutas empíricas narradas.

O princípio da legalidade estrita, além de ser garantia fundamental de um sistema penal cognitivo, é também "regra semântica metalegal de formação da linguagem legal" (FERRAJOLI, 2002, p. 99).

Os elementos constitutivos do delito traduzem, nos atuais sistemas penais, a exatidão da linguagem defendida por Ferrajoli, ou seja, a previsão clara da ação, do resultado e da culpabilidade é contemporânea do sistema garantista.

Quaisquer que sejam esses elementos, existe "um nexo metalógico entre a precisão de sua conotação legal e a determinabilidade de seu campo de denotação" (FERRAJOLI, 2002, p. 99). Isso significa que esse nexo se situa entre a legalidade e a verificabilidade, de igual forma entre a semântica legislativa e o cognitivismo judicial.

Podemos afirmar que a utilização de palavras vagas, além do emprego de juízos meramente valorativos, tanto na descrição dos fatos quanto na produção probatória, viola as garantias penais e processuais e fere o modelo garantista. Essa violação pode ser empreendida pelo juiz no momento do pronunciamento judicial, como também pelo legislador no momento da produção legislativa.

Dessa forma, o poder de denotação do juiz nada mais é que a regra da metodologia garantista a qual prevê a imprescindibilidade da linguagem penal determinada como condição de verificabilidade e refutabilidade jurídicas. Como já visto, esta linguagem refere-se tanto à aplicada pelo juiz quanto à utilizada pelo legislador. Não se pode admitir a vagueza e inexatidão nos conceitos penais.

\subsection{Poder de Comprovação}

No que se refere ao segundo poder atribuído ao juiz, poder de comprovação probatória, ainda dentro da análise da verdade processual, percebemos que a 


\section{A METODOLOGIA DE LUIGI FERRAJOLI PARA A PRODUÇÃO DE PRONUNCIAMENTOS JUDICIAIS PENAIS}

verificabilidade e refutabilidade se darão no plano empírico. Esse aspecto possui especial relevância pois relaciona-se à análise da prova.

O método utilizado nesse segundo poder é o método indutivo. "A interpretação da indução judicial como dedução mascarada é o equivocado paralogismo sobre o qual se baseia o sistema das provas legais" (FERRAJOLI, 2002, p. 108). Isso porque, no método indutivo, a verdade das conclusões é apenas uma verdade provável e não existem regras que garantam, com certeza, a verdade do processo de indução. Nesse sentido, o sistema legal de provas, quando enuncia, por exemplo, a confissão como a rainha das provas, atribuindo um valor superior às demais, equivoca-se na metodologia aplicada.

O sistema legal de provas é superado após a Revolução Francesa, momento no qual adota-se o sistema da livre convicção do juiz. Esse modelo também possui suas imperfeições. O princípio da livre convicção nada mais é que o reconhecimento da insuficiência das provas legais como determinantes da condenação e da pena (FERRAJOLI, 2002). Entretanto, esse princípio, na forma como foi concebido, foi responsável por momentos politicamente amargos e intelectualmente deprimentes das instituições penais (FERRAJOLI, 2002).

Podemos perceber que a própria denominação "livre convicção" nos mostra a subjetividade da atividade a ser desenvolvida, apresentando-se assim através de critérios extralegais, de juízos valorativos, que extrapolam a função de julgador. Não sem razão esse princípio é concebido como legitimador do arbítrio judicial, violando o modelo garantista.

Nesse ponto, Ferrajoli desenvolve mais uma regra da metodologia garantista, na medida mais aproximada da metodologia cientifica, como forma de legitimar o pronunciamento judicial como produto da ciência do direito. Isso porque, diferentemente da indução e explicação científicas, a indução judicial se refere a fatos acontecidos no passado e que não são mais repetíveis. (FERRAJOLI, 2002).

Diante da impossibilidade de confirmação através de experimento, como é realizado no âmbito da ciência, a indução judicial, aplicada na análise probatória, confirma ou refuta as provas considerando o grau de confiabilidade dos meios com os quais elas foram obtidas. Ferrajoli afirma que o grau de probabilidade do processo de 
indução judicial é de toda forma menor que o das leis científicas porque sua relação é com grau de probabilidade das máximas de experiência (FERRAJOLI, 2002).

Importante registrar que, segundo o citado autor, esse distanciamento do caráter científico traduzido no grau de probabilidade e, consequentemente, no método indutivo judicial utilizado para a análise probatória, não interfere na estrutura lógica da justificação (FERRAJOLI, 2002).

Observamos assim que a justificação da indução fática realizada no processo possui três condições, quais sejam, o ônus da acusação de demonstrar, através da prova, a veracidade dos fatos narrados na peça acusatória; o direito de defesa de apresentar contraprovas refutando as hipóteses da acusação e, uma vez assim agindo, haverá o consequente ônus da acusação de invalidar a refutação; e a faculdade do juiz de acolher ou não a hipótese acusatória, dependendo do conjunto probatório apresentado pela acusação e das refutações feitas pela defesa.

Essa faculdade do juiz, no modelo garantista proposto por Ferrajoli, não se satisfaz tão somente na aplicação do princípio da livre convicção, pois é necessário que exista uma metodologia apta a reduzir os subjetivismos e aproximar os pronunciamentos judiciais do campo da ciência.

Conforme já explanado, a ausência do experimento consequente da análise de fatos ocorridos no passado e não mais repetíveis, afasta a indução judicial da investigação científica. Entretanto, é possível se chegar ao critério do grau de probabilidade para a aceitação de uma hipótese acusatória na máxima medida de aproximação dos moldes científicos.

Para isso, Ferrajoli (2002) enumera as garantias processuais da necessidade da prova, da possibilidade da refutação e da convicção justificada como indispensáveis à construção do pronunciamento judicial através do uso de uma metodologia mais aproximada da científica.

Uma das regras desenvolvidas por Ferrajoli diz respeito à aplicação da teoria das provas legais negativas como garantia, inserida no modelo garantista, contra o arbítrio judicial, pois prevê a imprescindibilidade normativa da prova e a presunção da inocência até prova em contrário (FERRAJOLI, 2002).

Entretanto, ainda que seja caracterizada como uma garantia processual, a prova legal negativa é criticada por Ferrajoli pois, assim como as provas legais 


\section{A METODOLOGIA DE LUIGI FERRAJOLI PARA A PRODUÇÃO DE PRONUNCIAMENTOS JUDICIAIS PENAIS}

positivas, ela não dispõe de critérios objetivos de aplicabilidade, seguindo assim a arbitrariedade de qualquer valoração legal. (FERRAJOLI, 2002).

O princípio do in dubio pro reo, típica prova legal negativa, não possui critérios objetivos de aplicabilidade, o que verificamos é a livre apreciação do juiz, utilizando-se de argumentos muitas vezes valorativos, para empregá-lo. É nesse sentido que a garantia se esvazia, pois, a ausência de objetividade do método de aplicação a transforma em mais uma medida de livre arbítrio do juiz.

A necessidade da prova, como regra metodológica na produção do pronunciamento judicial, é de simples análise. Isso porque é de conhecimento geral que a hipótese acusatória, dentro do sistema penal, deve ser confirmada pelas provas produzidas ou dados probatórios colacionados aos autos.

Entretanto, Ferrajoli eleva a necessidade da prova ao nível de garantia processual, quando exige a pluralidade de provas como condição de confirmação da hipótese acusatória (FERRAJOLI, 2002). Nesse sentido, não basta, por exemplo a confissão do acusado, ou qualquer outra prova isolada no processo, é necessária a harmonia e coerência de todo o acervo probatório.

O citado autor argumenta que o contraditório processual ainda é mais importante que a garantia da necessidade da prova, isso porque é através da garantia do contraditório que se torna possível a refutação da hipótese acusatória, ou seja, da demonstração da contraprova (FERRAJOLI, 2002).

Podemos concluir que a garantia do contraditório, como regra metodológica do pronunciamento judicial, equivale, analogicamente, à refutação das hipóteses na investigação científica. Dessa forma, para que uma hipótese acusatória seja aceita não basta sua demonstração, mas é imprescindível a superação das possíveis refutações.

Importante ressaltar que, ainda que seja necessária a pluralidade de provas como garantia processual, é suficiente apenas uma refutação aceita como verdadeira para afastar a verdade da hipótese acusatória. Nesse ponto, Ferrajoli afirma que o princípio da livre convicção do juiz ainda que seja capaz de justificar as provas, não pode superar as contraprovas. (FERRAJOLI, 2002).

Nesse sentido, a hipótese acusatória não deve somente ser confirmada pela pluralidade das provas apresentadas, mas também não ser refutada pela defesa ou, uma vez refutada, devendo prevalecer sobre todas as contraprovas (FERRAJOLI, 2002). 
Observamos que ainda que não sejam refutadas as hipóteses da acusação, ou as hipóteses em conflito com ela, a decisão se impõe, como consequência do non liquet, nesse caso haverá a aplicação do princípio do in dubio pro reo.

Da análise dessas três garantias processuais, enumeradas por Ferrajoli como regras na construção do pronunciamento judicial, verificamos que elas se consubstanciam na triangulação processual, ou seja, acusação, defesa e juízo. De modo que essa separação é imprescindível para a análise das provas e contraprovas realizada pelo juiz, sob o manto da imparcialidade. E, não havendo conclusão acerca da verdade da hipótese acusatória deve ser aplicada a regra do favor rei.

Para Ferrajoli, essas três garantias possuem caráter apenas epistemológico, e não jurídico, se delas se extrair a regra do in dubio pro reo, isso porque, na análise do autor, essas garantias "não predeterminam normativamente a valoração das provas, mas simplesmente refletem, na investigação judicial, a lógica da indução científica" (FERRAJOLI, 2002, p. 122).

A investigação judicial não se limita a uma busca restritamente intelectual, ela é o pressuposto de decisões acerca da liberdade dos indivíduos, decisões nas quais o poder prevalece sobre o saber, quando há a ausência de limites normativos (FERRAJOLI, 2002).

Desta feita, a garantia da necessidade da prova quando não concretizada através da exigência de pluralidade de provas como ônus da acusação se transforma num critério vago da íntima convicção.

Da mesma forma, a garantia da possibilidade de refutação pela defesa, quando não é implementada através de mecanismos semelhantes aos atribuídos legalmente à acusação, transforma-se em princípio genérico referente às razões do acusado.

E, por último, a função atribuída ao juiz, de escolher entre as hipóteses conflitantes, quando não vinculada a nenhuma norma jurídica que normatize a prova e a contraprova, a hipótese e a refutação, e quando a motivação da decisão acerca da verdade fática analisada não disponha de todas as inferências indutivas e dedutivas que a fundamentam, essa decisão converte-se em argumentação puramente valorativa, ausente de critérios de verificação e de controle (FERRAJOLI, 2002). 


\subsection{Poder de conotação}

O terceiro poder atribuído ao juiz, por Ferrajoli, na construção de regras metodológicas para a legitimidade do pronunciamento judicial enquanto produto da ciência do direito é o poder de conotação.

A objetividade buscada nos dois poderes anteriormente explicitados não enuncia que a produção da decisão judicial é uma tarefa exclusivamente extravalorativa. Ainda que os poderes de denotação ou verificação jurídica e de comprovação ou verificação fática necessitem de um caráter objetivo na sua aplicação, o poder de conotação não segue esse viés.

Ao analisar o cometimento do delito, ainda que este esteja denotado taxativamente na lei, o juiz não fica adstrito apenas a acolher ou afastar a hipótese acusatória diante da comprovação pela indução fática.

O delito, como um fato complexo, vai além da previsão legislativa que não possui a capacidade de dispor de todas as nuances das condutas delitivas. Nesse sentido, é através do poder de conotação que o juiz emprega a equidade como uma das regras metodológicas na construção da sua decisão.

Ferrajoli explica que as teses descritivas de circunstâncias penais específicas, ainda que se utilizem de afirmações constantes de referências empíricas, não são idôneas a predicar a verdade jurídica (FERRAJOLI, 2002). Isso porque, conforme dito acima, é impossível a previsão legal de todas as infinitas conotações particulares do delito, sejam elas as atenuações ou os agravamentos das condutas. Desta feita, "a individualização das características particulares do fato e as consequentes valorações configuram a chamada equidade do juízo" (FERRAJOLI, 2002, p. 125).

É justamente nessa equidade do juízo que o poder de conotação se expressa. Ferrajoli afirma que quanto maior o conhecimento do juiz acerca do fato delituoso, suas nuances e complexidades, maior será a atenuação de sua gravidade, isso porque a compreensão humana possui tendência simpatética (FERRAJOLI, 2002).

A valoração equitativa somente é possível diante do caso concreto, não há possibilidade de manifestação da equidade abstratamente. Isso não significa, segundo as lições de Ferrajoli, que o juiz deve se identificar com os hábitos mentais do acusado que esteja sendo julgado, mas sim que ele promova um esforço para se distanciar de suas 
próprias ideologias e preconceitos e, consequentemente, passe a compreender as ideologias e inclinações do sujeito em julgamento (FERRAJOLI, 2002).

Desse modo, podemos afirmar que essa compreensão equitativa, compreendida no poder de conotação do juiz, corresponde a uma condição de sua imparcialidade.

Ferrajoli defende, diante da aplicação da equidade, que a codificação penal deveria dispor não somente de atenuantes genéricas, mas também de eximentes genéricas, ou seja, algumas situações a serem analisadas pelo juiz possibilitariam a exclusão do delito aplicando a eximente genérica, que se assemelha ao perdão judicial aplicável em delitos determinados (FERRAJOLI, 2002).

Concluímos que, apesar do poder de conotação dispor acerca da valoração equitativa do juiz no julgamento do fato delituoso, esta valoração não se confunde com juízos pessoais, amparados em ideologias e preconceitos do julgador, mas sim na compreensão fundada sempre no favor rei, na aproximação das inclinações do sujeito em julgamento.

\subsection{Poder de disposição}

O último poder do juiz a ser analisado neste trabalho é o poder de disposição que está relacionado à margem de discricionariedade do juiz na produção da decisão judicial.

Importante esclarecer que a segurança de um pronunciamento judicial, ainda que amparado e fundamentado normativamente, não é absoluta. Isso porque "todos os espaços de insegurança - irredutíveis e redutíveis - equivalem a outros tantos espaços ou tipos de poder, cuja soma constitui o que chamamos de "poder judicial"" (FERRAJOLI, 2002, p. 133).

Já expomos neste trabalho o poder de verificação jurídica e o poder de verificação fática, relacionados à verdade processual, e compreendemos que eles são analisados dentro de espaços mínimos e irredutíveis, diante das regras metodológica, já explicitadas, relacionadas à verdade processual.

Por sua vez, o poder de disposição é exercido em espaços redutíveis, considerando que as decisões são amparadas em valores distintos da verdade 
(FERRAJOLI, 2002). Dessa forma, os três primeiros poderes explanados por Ferrajoli, e aqui já analisados, são intrínsecos à função jurisdicional.

Noutro pórtico, o poder de disposição "é sempre o produto de carências ou imperfeições do sistema e como tal é patológico e está em contradição com a natureza da jurisdição" (FERRAJOLI, 2002, p. 134).

Assim, verificamos que o poder de disposição é inversamente proporcional aos três poderes anteriores. Isso se deve ao fato de que quanto maior for o espaço de inseguranças na análise cognitiva, ou seja, quanto menor for a análise acerca da verdade processual, maior será a discricionariedade do juiz, ou seja, seu poder de disposição.

Consequentemente, a verdade processual é alcançada através das regras metodológicas garantistas, que, conforme já explanado aqui, garantem a refutação da hipótese acusatória, de modo que, o sistema que não disponha dessa possibilidade de refutação se torna potestativo, amparado em juízos de valor e não na atividade cognitiva (FERRAJOLI, 2002).

Ferrajoli exemplifica a intensidade do poder de disposição diante de termos vagos e indeterminados constantes da lei, como "subversivo" ou "obsceno", que não permitem a verificação probatória da hipótese acusatória, diante do estatuto semântico meramente valorativo, de igual forma, não permite a refutação da defesa (FERRAJOLI, 2002). Por esta razão, não há o exercício próprio da jurisdição na atividade empreendida em casos dessa natureza, uma vez que não há juízo de comprovação, nesse ponto o poder discricionário do juiz se torna predominante, muitas vezes adentrando na arbitrariedade.

Diante disso, visualizamos a importância de uma metodologia para a produção do pronunciamento judicial, uma vez que é preciso impor limites à atividade judicial na mesma medida em que a ciência do direito deve adotar, dentro de suas possibilidades, a cientificidade na elaboração das decisões.

O poder judicial de disposição que, segundo Ferrajoli, é gerado pela carência de garantias normativas predominando, consequentemente, o direito penal arbitrário, é distinto do poder judicial de verificação porque as decisões advindas do primeiro não tratam da verdade mas sim de outros valores (FERRAJOLI, 2002). Como consequência dessa constatação percebemos que o poder de disposição introduz a natureza política na atividade judicial, além da legal e equitativa. 
Então, verificamos que, se no campo cognitivo há espaços para a incerteza, cresce o poder de disposição e consequentemente o decisionismo judicial, amparado em critérios subjetivos do juiz, critérios de justiça substancial ou critérios políticos (FERRAJOLI, 2002).

No exemplo citado pelo autor aqui referido, acerca da indeterminação e vagueza de termos constantes na lei, como "subversivo" ou "obsceno", observação que a análise do juiz é meramente valorativa, conforme suas concepções pessoais acerca de subversão e obscenidade.

Os ordenamentos democráticos que se intitulam de "Estado de Direito" esse poder de disposição deveria estar reservado exclusivamente à lei, por se tratar de um poder de natureza também política (FERRAJOLI, 2002). De modo que haveria uma ilegitimidade política do julgador para proceder à aplicação deste poder, tendo em vista que as decisões acerca de questões de ordem subjetiva da sociedade devem ser decididas pelos responsáveis pela produção legislativa e não através de pronunciamentos judiciais.

Entretanto, isso não significa que uma decisão judicial penal amparada no poder de disposição do juiz, apesar de não dispor acerca da verdade processual, não seja justificada. A motivação existe, porém, é uma motivação baseada não numa análise cognitiva, e sim valorativa. Uma vez que a análise não é cognitiva, não há possibilidade de efetivar os processos de comprovação e refutação. A análise meramente valorativa, amparada em juízos de valor, possibilita a argumentação e o controle pragmático de aceitação que, não passam de princípios gerais do ordenamento, ou princípios políticos, muitos dos quais dispensam o poder de verificação (FERRAJOLI, 2002).

Ainda que possuam valor normativo, esses princípios gerais, quando utilizados como critério justificador das decisões punitivas, apenas vinculam essas decisões (FERRAJOLI, 2002). Uma vez que foram tomadas levando em conta as ideologias e preconceitos do julgador, distante do exercício cognitivo, da aplicação da verificação e refutação, da metodologia a ser aplicada no produto da ciência do Direito.

Registramos que o garantismo e sua proposta metodológica não defende o legalismo e a concepção do juiz como uma máquina automática. A proposta argumenta que a neutralidade do juiz corresponde mais à sua honestidade intelectual que à isenção ideológica (FERRAJOLI, 2002). O que deve ser verificado é o desinteresse pessoal no 


\section{A METODOLOGIA DE LUIGI FERRAJOLI PARA A PRODUÇÃO DE PRONUNCIAMENTOS JUDICIAIS PENAIS}

caso concreto, não somente no âmbito da triangulação processual, mas em todo o contexto no qual o fato analisado se insere.

\section{CONCLUSÃO}

A analogia empreendida por Popper acerca da definição do xadrez através de suas regras e da ciência através de regras metodológicas é ampliada aos pronunciamentos judiciais penais, segundo o pensamento de Luigi Ferrajoli.

Desse modo, concluímos que somente se legitima um pronunciamento judicial penal enquanto obedecer às regras metodológicas do sistema garantista. Isso porque, uma decisão judicial proferida sem a devida aplicação dos poderes aqui analisados, não pode ser reconhecida como produto da ciência do Direito, mas sim como mera opinião do juiz motivada através da utilização errônea dos princípios gerais.

A distinção entre direito e moral é lição básica proferida ainda nos primeiros anos da vida acadêmica. Este trabalho não objetivou retomar essa distinção, mas tratou de demonstrar de que forma contaminamos o direito com a moral. Não somente o julgador promove essa contaminação, ela tem início já na produção legislativa, quando são utilizados termos vagos e indeterminados que somente podem ser interpretados através da análise pessoal, subjetiva, eivada de preconceitos e ideologias.

A atividade de construção do pronunciamento judicial deve se assemelhar, na medida máxima, à investigação científica. Os passos que aqui foram traçados, desde o poder de denotação, no qual o juiz interpreta de forma objetiva se há a subsunção dos fatos às normas, passando pelo poder de comprovação, no qual é empreendido o exercício de verificabilidade e refutabilidade das hipóteses acusatórias, chegando ao poder de conotação, através do qual o juiz se afasta de seus preconceitos e ideologias para compreender as inclinações do acusado, no intuito de agir com equidade e, por fim, encerrando-se com o poder de disposição que deve estar sempre delimitado juridicamente, com o fim de reduzir a discricionariedade e consequentes arbitrariedades judiciais, são regras caraterizadoras dos pronunciamentos judiciais em um Estado de Direito.

Da mesma maneira que o xadrez é, segundo Popper (2008), caracterizado por suas regras e a ciência pelas regras metodológicas, o pronunciamento judicial, 
somente se legitima enquanto produto da ciência do direito se puder ser caracterizado pelas regras desenvolvidas no sistema garantista, previsto na nossa Constituição Federal.

\section{REFERÊNCIAS}

BOBBIO, Norberto. Teoria do ordenamento jurídico. $6^{\text {a }}$ Edição. Editora: Universidade de Brasília, 1995.

FERRAJOLI, Luigi. Direito e razão: teoria do garantismo penal. $3^{\text {a }}$ Edição Revista. Editora: Revista dos Tribunais, 2002.

POPPER, Karl Raimund. A lógica da pesquisa científica. $16^{\circ}$ Edição. Editora Cultrix, 2008.

TOLEDO, Francisco de Assis. Princípios Básicos do Direito Penal. $5^{\text {a }}$ Edição. Editora Saraiva, 2002. 